\title{
Performance assessment of a 619kW photovoltaic power plant in the northeast of peninsular Malaysia
}

\author{
M. Nirrmahl Raj ${ }^{1}$, Jagadeesh Pasupuleti ${ }^{2}$ \\ ${ }^{1}$ College of Graduate Studies, Universiti Tenaga Nasional (UNITEN), Malaysia \\ ${ }^{2}$ Institute of Sustainable Energy, Universiti Tenaga Nasional (UNITEN), Malaysia
}

\begin{abstract}
Article Info
Article history:

ABSTRACT
Photovoltaic (PV) power plants are becoming widely implemented and in
larger scale around the world. Understanding performance criteria is crucial
in the benchmark of PV plants and ascertaining performance requirements
during both design and operational stage of a PV plant. Performance ratio
(PR) and capacity factor (CF) are two generally accepted benchmarks for
the assessment of a grid connected PV plant. However, within the South East
Asia region, and especially within Malaysia, there is a lack of compilation
and benchmark for the PR and CF values of existing and operational PV
plants. This lack of data is disadvantageous for the designing and assessment
of performance of any PV plants in the area. Thus, the focus of this study is
to assess the PR and CF performance a $619 \mathrm{~kW} \mathrm{PV} \mathrm{plant} \mathrm{in} \mathrm{the} \mathrm{Northeast} \mathrm{of}$
Peninsular Malaysia, with the ultimate goal of proposing a standard.
From the continuous operation of the said PV plant for the duration of one
year, the plant energy production has been obtained and is compared with
the simulated energy generation model. Based on the comparison, the plant is
determined to be operating with PR value of 0.77 and CF value of $12 \%$.
The plant is evaluated to be operating within benchmark values. These values
not only verify the performance of the studied PV plant, they also present a
form of comparison for future studies.

Received Feb 29, 2020

Revised Apr 1, 2020

Accepted Apr 15, 2020

\section{Keywords:}

Capacity factor

Meteonorm

Performance ratio

PV power plant

PVSyst
\end{abstract}

Copyright (C) 2020 Institute of Advanced Engineering and Science. All rights reserved.

\section{Corresponding Author:}

M. Nirrmahl Raj,

College of Graduate Studies, Universiti Tenaga Nasional, Jalan Ikram-Uniten, 43000 Kajang, Selangor, Malaysia.

Email: nirmal881111@gmail.com

\section{INTRODUCTION}

There has been tremendous expansion of the global renewable energy source market. A portion of this expansion can be contributed to the continuously increasing numbers and size of PV plants [1]. In Malaysia, as portion of increasing demand [2], the renewable energy power targets as share of electricity generation is predicted to increase to $9 \%$ by 2020 and $11 \%$ by 2030 . Solar PV generation capacity allocation of 563MW alone have been awarded in year 2017. This points to increasingly greater portion of the energy generation capacity coming from PV sources for Malaysia in the future [3]. For PV plants, the energy generation is not constant, unlike other forms of energy such as nuclear and thermal. Part of the reason is the availability of sunlight is only for roughly half a day. Weather patterns also have great impact of the functioning of the PV plants. Thus, the performance of PV plants correlates highly with these external variables. The performance of PV plants is an indicator of suitability of design parameters and operational health. In view of this, an industry wide benchmark system for the PV plant performance criteria is important.

There are several parameters to assess the performance of a PV plant. Yield and Capacity Factor are important indicators of PV system performance, defined by ratio of energy output of PV system (kWh) to the nominal DC power $(\mathrm{kW})$. The performance ratio of a PV plant on the other hand is the portion of energy available for export into grid after taking into consideration various system losses, degradation, environmental factors 
and etc. [4]. Furthermore, the viability of a PV plant is highly dependent on the efficiency of long-term energy yield. Intermittency, volatility, location of the plant and characteristics of solar cells also play crucial role in the forecasting and planning of a PV plant generation capacity [5, 6]. Detailed assessment of these performance factors would provide design guidelines for new PV plants in design, and also energy generation targets during plant operation. Furthermore, the CF and PR values would provide insight into external variables impact to the PV plant generation capacity, allowing for better forecasting, maintenance and grid management in terms of energy availability [7]. Studies have been conducted on various PV plants to determine the performance ratios and establishing methodologies [8, 9]. The detailed assessment of these performance factors would reveal energy generation pattern in relation with external factors such as weather. This would also contribute to predicting the impact of fluctuation in PV plant generation capacity on stability of connected grid as studied in various papers [10-16]. Determining and monitoring the performance of PV plants is crucial where impact of energy generation fluctuation on local grid is of importance.

This paper studies the energy generation model of the $619 \mathrm{~kW}$ PV plant for over a period of 1-year. Simulated or theoretical long-term energy generation data can be generated using historical meteorological data with solar system simulation software, PVSyst, to simulate the yearly energy generation. Compiled monthly energy generation data comparison with the simulated generation data allows for analysis of monthly energy production pattern. From the assessment and comparison, the PR and CF values of the PV plant can be calculated for the particular year. The indication from these calculated performance criteria are positive. The PR and CF values fall within the global average. The outcome is able to prove the design and implementation of the PV plant as acceptable. This paper then present the performance assessment of the PV plant and with comparison to global benchmarks values, the particular concern for a region-based benchmark is due to specific weather patterns that effect only certain regional areas and therefore performance of PV plants is not directly equivalent in terms of comparison criteria. This region-specific weather events reduce comparability with global benchmark. Hence, a region-based benchmark especially for within Malaysia is highly recommended.

\section{PV PLANT DESIGN AND GRID CONNECTION}

The $619 \mathrm{~kW}$ PV plant is located in the northern state of Kelantan, in the Malaysian Peninsula. The PV plant itself is located above a 5-storey municipal carpark block, where the solar roof encompasses the entire roof carpark area and acts as shade for the carpark below. The PV roof is split into 2 halves; the North Roof and South Roof. The North roof is tilted at $20^{\circ}$ and to an azimuth of $180^{\circ}$, while for South Roof is tilted at $16^{\circ}$ and to an azimuth of $0^{\circ}$. A connection of total 2,960 pieces PV panels make up the entire PV roof. The solar power plant is designed to cater for the maximum numbers of solar panels and utilising the space available effectively. The system is designed around the open circuit voltage of maximum $1000 \mathrm{~V}$. This design parameter is set based on maximum input DC voltage of inverter, combiner box, insulation level of PV panels and other components of $1000 \mathrm{~V}$. The PV plant is rated to $619 \mathrm{kWp}$.

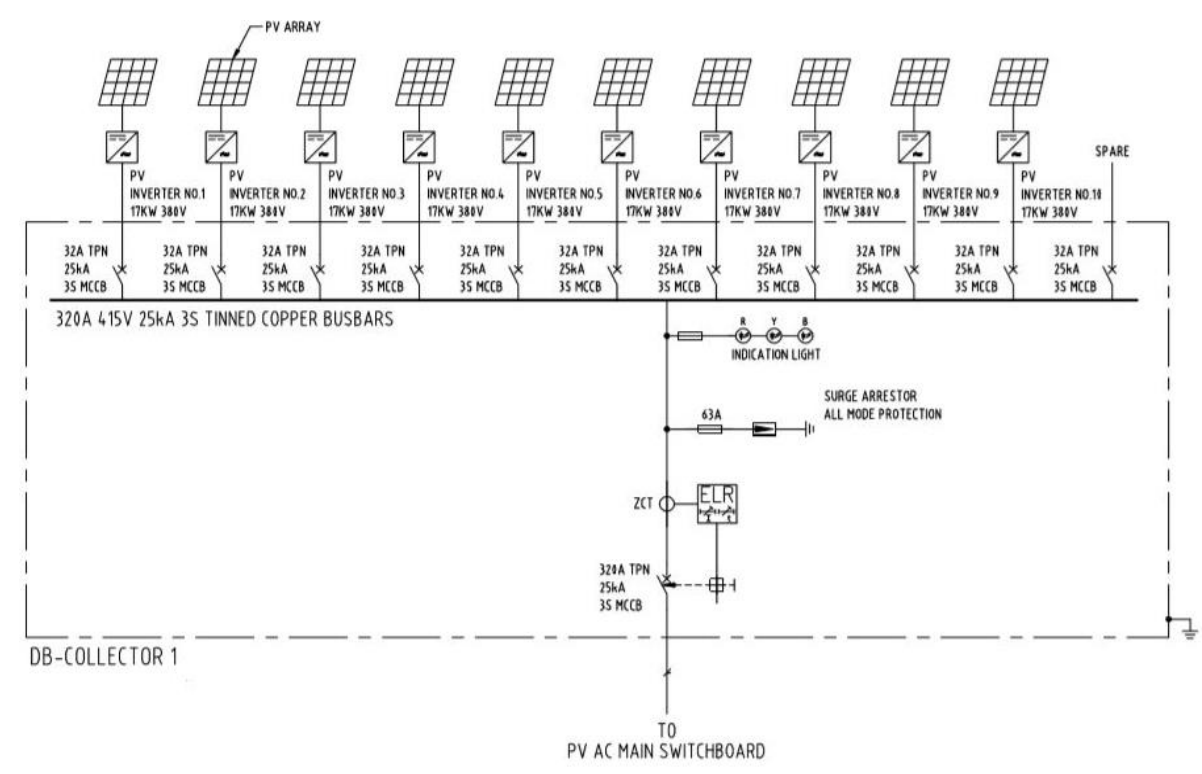

Figure 1. DC Side circuit design 
The Figures 1 and 2 present the overall arrangement of the components and connection diagram for both DC side and AC side. The PV plant is a grid-connected plant, and there is no energy storage medium such as batteries. Thus, the energy generated at any point during the day is directly transmitted into the local grid at $11 \mathrm{kV}$ voltage level. Energy generated is transformed to $11 \mathrm{kV}$ voltage level using an on-site step-up transformer in a compact substation. The point of common coupling (PCC) is the TNB pencawang elektrik (P/E) located within the carpark building. Energy generation measurement point, energy meter, is shown in Figure 3. The point of measurement being at the PCC takes into account the total energy generated by the PV plant.

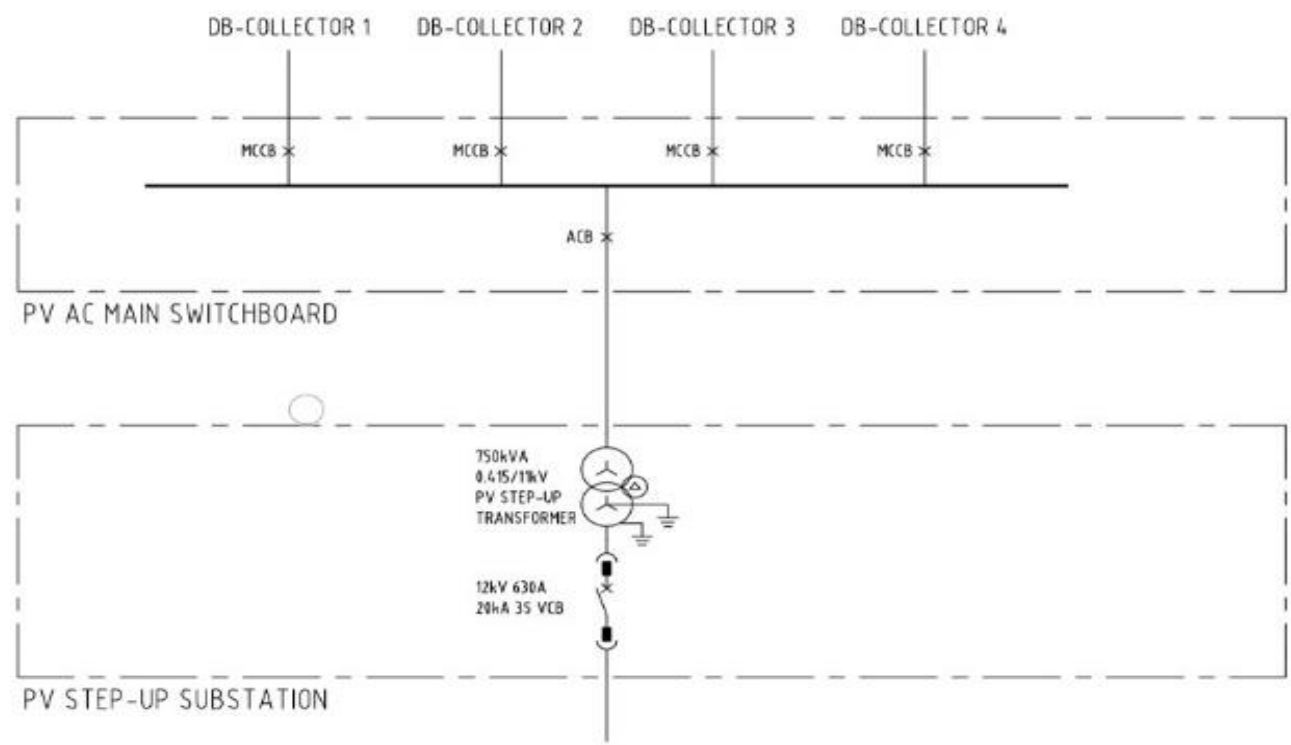

Figure 2. AC side circuit design of combiner box

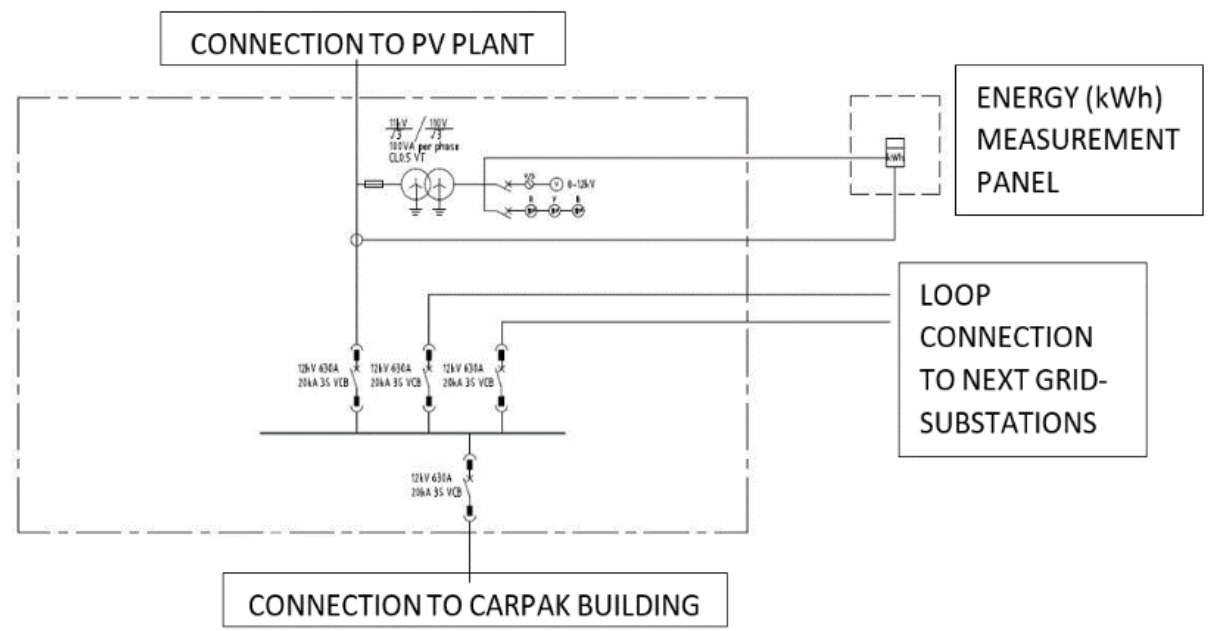

Figure 3. PV plant connection diagram with local grid connection

\section{ENERGY MEASUREMENT AND PERFORMANCE CALCULATION}

Over the period of October to March, the East Coast region of the Malaysian Peninsula undergoes monsoon season. The energy generation from PV plant thus drop due to the adverse effect of heavy rain, and frequent cloud coverage. The performance of the PV plant during this period also reduces. Nevertheless, the energy generation is continuous during the entire period. In actual installation environment, the PV panels and overall PV system are impacted by various conditions which alter the performance on the PV plant and must be taken into consideration during the design of the PV system [17]. 
From the energy meter at the Point of Common Coupling (PCC), the energy generation is recorded at monthly interval to plot an energy generation profile for a 1-year period. Figure 4 provides the plot of energy measured from the PV plant. A drop in energy generation especially from October onwards is seen with the coinciding monsoon season which brings frequent rain and increased duration of cloud cover to the East Coast region of the Malaysian Peninsula. The actual site energy produced obtained from plant is $652,146.00 \mathrm{kWh}$ for the 1-year period.

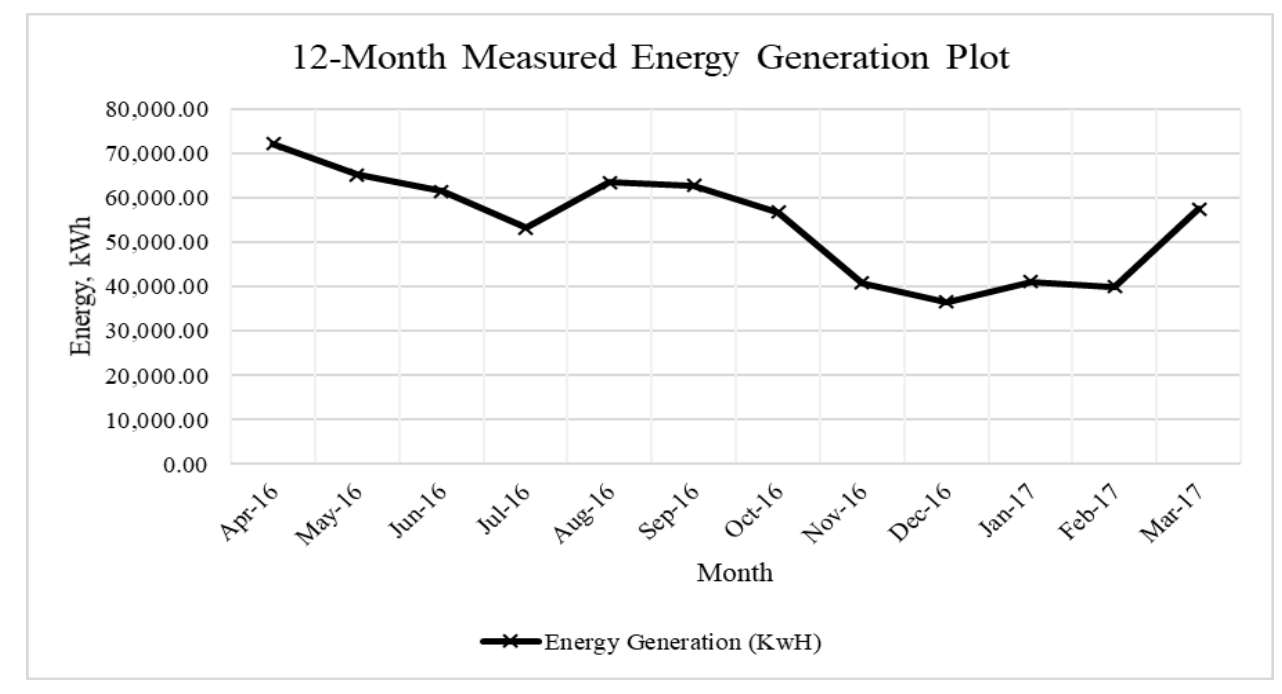

Figure 4. 12-month measured energy generation plot

Meteorological data is imported from the Meteonorm Software. The Meteonorm Software collects and provides historical meteorological data for various regions in the worlds. The meteorological input for the 1-year period of study includes solar irradiation data, sunshine duration, temperature readings and also precipitation data. The data is imported into PVSyst software, which is a generally used software for the purpose of solar system simulation. PVSyst software was designed for varios simulation of solar system installations. Using the meteorological data, and the solar power plant design parameters, the software is used to generate the expected energy generation profile for the PV plant for a 1-year period. The simulation results are plotted against the actual measured generation data for performance comparison purpose in the Figure 5 .

From the comparison between measured and simulated energy generation data, the percentage shortfall in actual energy generation varies from 10\% in April 2016 to $41 \%$ in February 2017. The shortfall in seen greater mainly during the November, December, January and February months which also coincides with the monsoon season in the state. From the PVSyst Software simulation, the estimated yearly energy production is $852,407 \mathrm{kWh}$ /year. Capacity for a PV plant is the maximum power generation rating. capacity factor $(\mathrm{CF})$ equation below shows the relation between the maximum output energy from a PV plant against the maximum theoretical output or total potential energy that can be generated from the same PV plant under ideal conditions for a given period of plant operation [4]. Thus, CF is the plant energy generation capacity availability indicator of a PV plant and can be derived either from the DC side or the AC side energy generated.

$$
\text { Capacity Factor }(\mathrm{CF})=\frac{\text { Total Energy Generated }}{(365 \text { days }) \times(24 \text { hours per day }) \times(\text { Peak Power })} \times 100 \%
$$

Performance ratio (PR) is the comparison between energy generation by a PV plant against calculated or simulated output. Meteorological data, system design and component losses, and others parameters are taken into consideration in the energy generation calculation. Therefore, PR value provides an indication of overall PV plant energy generation efficiency against the rated output under specified conditions. PR value allows comparison between PV plants that are located in various locations and weather. This is due to better representation of insolation in its calculation. PR value also on the other hand, indicate the PV plant losses due to various reasons including system faults, weather shading and others. PR of a PV plant is highly correlated with the weather pattern. The standard PR reporting can be monthly, annually, or even within specific time frame, i.e. daily. The tracking of PR value can provide information on existence of issues with the PV plant that are impacting the performance. 


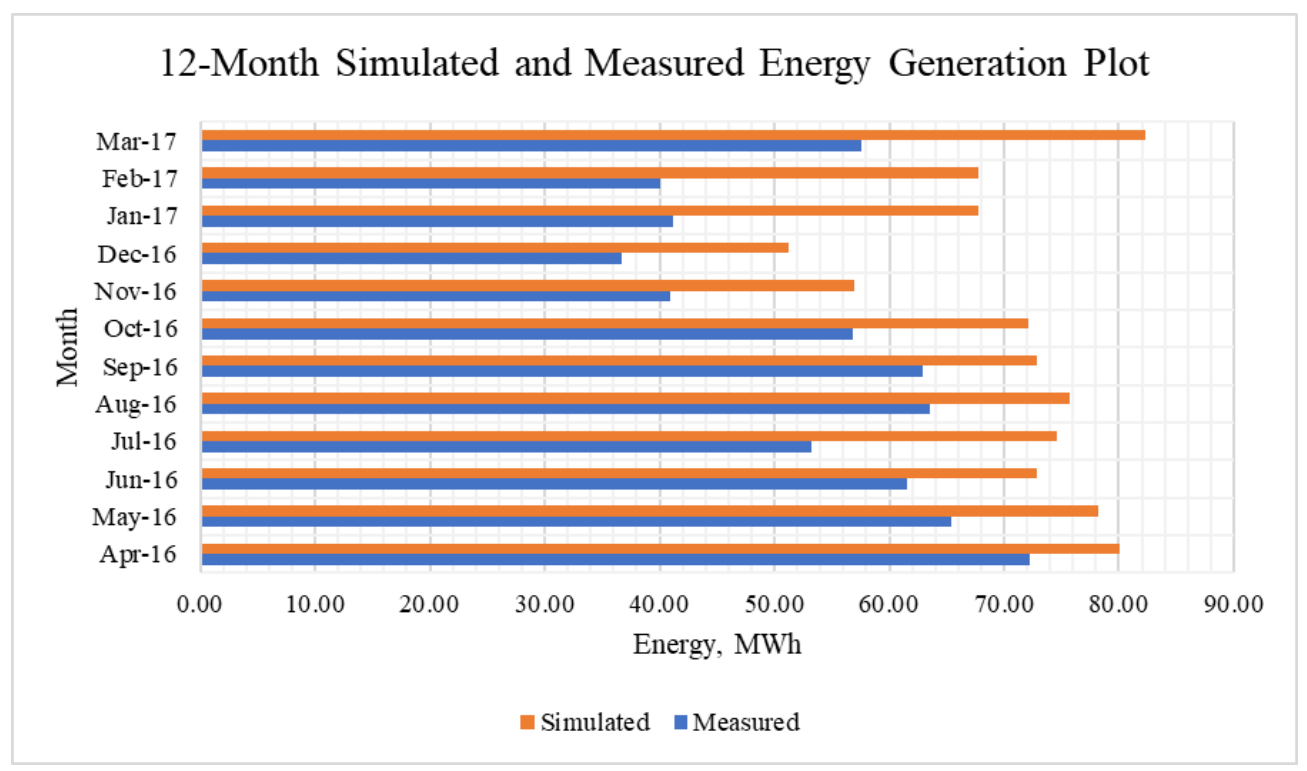

Figure 5. 12-month simulated and measured energy generation plot

PR calculation methods are various. Solar power plant industry participants including relevant standards and organisations have proposed and defined PR calculation methods. The IEC 61724 [18], NREL [19, 20], and IEA PVPS TASK2 [21, 22] standards describe PR as the ratio of system final yield against reference yield. While the SMA standard calculation is based on energy exported to grid after the deduction of energy loss which includes thermal losses, conduction losses and others, and energy consumption for internal PV plant operation. Using the SMA method which presents the PR equation as bescribed below, the actual site annual power generation is compared against the simulated generation via below formula.

$$
\mathrm{PR}=\frac{\text { Actual reading of plant output in kWh pa. a }}{\text { Nominal, calculated plant output in kWh pa.a }}
$$

\section{RESULTS AND DISCUSSION}

Generally, Capacity Factor values globally are increasing from 14\% to $18 \%$ for years 2010 to 2018 . However, these are global weighted average CF values for utility scale PV systems as recorded by IRENA. On an individual basis, PV plants would endure CF of highly variating value, as performance of the plants are highly tied to the local weather pattern and other operating conditions of the respective plants. The CF for this PV plant is $12 \%$. This indicates the plant is operating at $12 \%$ energy generation of the theoretical maximum energy output possible. Taking into account that sunlight is only available for a limited period of a day, the CF values for PV plants in general would be lower compared to other forms of non-fossil fuel energy sources such as nuclear energy, thermal energy and etc. which for example in case of nuclear energy, have $\mathrm{CF}$ values of $80 \%$ or greater. Also, $\mathrm{CF}$ values for renewable energy power plants such as collar and wind undergo non-constant power output due to dependence on weather pattern which may vary greatly depending on region [23]. This is intermittence, and the CF values will be lower for these plants. Hence, a comparable CF benchmark of PV plants would allow for better regional comparison of PV plants performance in relation to changing technology, regional weather patterns and various other variables including availability of technology to particular region.

The calculated performance ratio (PR) is 0.77. From the study conducted by Woyte et al., [24], PR values for Worldwide Sources averaged 0.65 to 0.70 in the $1990 \mathrm{~s}$, and in the years 2000s for countries like Germany, the PV values averaged 0.84 , and Taiwan, the PR values averaged 0.74 . Additionally, based on report publication by IEA in 2014, the PR values have been increasing from $50 \%-75 \%$ in the late 1980 s, to $70 \%-80 \%$ in the $1990 \mathrm{~s}$, and $>80 \%$ in present. There are also instances where the PR ratio have reached $90 \%$. However, this presence of variance in the PR values ranging 70\%-90\% across different newly installed PV systems necessitate the assessment and study of performance of the installed PV systems [25]. Thus, the comparison with available PR data for years 2000s indicates acceptable PR value, although not superior. Overall, the PR of this PV plant indicates efficient operation for the 1-year period. 


\section{CONCLUSION}

The 1-year period performance of the PV plant was evaluated based on two benchmarks, performance ratio (PR) and capacity factor (CF). Evaluation method is described for PR and CF. The evaluation process makes use of recorded actual generation data and simulated generation data. Historical meteorological data from Meteonorm is used in the PVSyst software simulation. From the calculations, the PR of the PV plant was determined as 0.77 , and $\mathrm{CF}$ as $12 \%$. The CF results for this PV plant falls within the scale of average recorded by IRENA. For the PR value, the obtained value falls between the recorded average PR value for Taiwan and Germany based on precedent study. The monsoon season also plays an important role in the energy generation capacity of the plant, as demonstrated in the drop of energy generation seen in both the measured and simulated generation data. In overall, the performance of the PV plant is found acceptable.

As aim of this study, the method of determining the PR and CF was successfully evaluated for the PV plant and presented in this paper. These two benchmarks are beneficial and enable the comparison of the performance of the PV plant against other plants within the region or globally. Benchmarks allow improvement of the PV plant operating target the and also provide base design criteria for future PV plants. This is in view of the lack of regional and especially local benchmark for both CF and PR of PV power plants, which is a drawback in the study process of PV plant performance. The comparison of PV plants in similar regions should provide better understanding and expected performance requirements of PV plants. Furthermore, the effect of monsoon season for example that has had on the studied PV plant cannot be directly compared with the scenarios in other countries. This gives support for local Malaysia based benchmark index for the performance rating of PV plants to be established.

\section{ACKNOWLEDGEMENTS}

This study was conducted with the influence and support of many people and organisations and was done within the stipulated requirements of the university. The authors would like to express utmost gratitude towards the assistance received in the completion of this study, especially information provided by the solar power plant company, who provided the necessary data to fulfil the objectives of the study.

\section{REFERENCES}

[1] IEA, "Technology Roadmap - Solar Photovoltaic Energy 2014," IEA, 2014.

[2] S. T. Malaysia, "Peninsular Malaysia Electricity Supply Outlook 2017," Suruhanjaya Tenaga Malaysia (Energy Commission), 2017.

[3] IEA, "Renewables 2018: Global Status Report," IEA, 2018.

[4] A. M. Khalid, I. Mitra, M. Warmuth and V. Schacht, "Performance Ratio-Crucial Parameter for Grid Connected PV Plants," Renewable and Sustainable Energy Reviews, vol. 65, pp. 1139-1159, 2016.

[5] S. Sayeef, S. Heslop, D. Cornforth, T. Moore, S. Percy, J. K. Ward, A. Berry and D. Rowe," Solar intermittency: Australia's clean energy challenge," Australian Solar Institute, 2012.

[6] M. El-Ahmar, A.-H. M. El-Sayed and A. M. Hemeida, "Mathematical Modeling of Photovoltaic Module and Evaluate the Effect of Various Parameters on its Performance," Conference: 2016 Eighteenth International Middle East Power Systems Conference (MEPCON), 2016.

[7] N. M. Kumar, R. P. Gupta, M. Mathew, A. Jayakumar, N. K. Singh, "Performance, Energy Loss and Degradation Prediction of Roof-Integrated Crystalline Solar PV System Installed in Northern India," Case Studies in Thermal Engineering, vol. 13, p. 100409, 2019.

[8] J. Raja, Nishant Jain, C. Christober Asir Rajan, "Grid Connected Mega-Watt Range Solar Power Plant in India: Experimental Measurement \& Performance Analysis," International Journal of Applied Power Engineering (IJAPE), vol. 8, no. 1, pp. 22-33, 2019.

[9] A. Jalal, S. Kamaruzzaman, F. Ahmad, "Performance of Grid-Connected Solar Photovoltaic Power Plants in the Middle East and North Africa," International Journal of Electrical and Computer Engineering (IJECE), vol. 9, no. 5, pp. 3375-3383, 2019.

[10] N. Dhlamini, "Solar photovoltaic generation and its integration impact on the existing power grid," 2018 IEEE PES/IAS Power Africa, Cape Town, pp. 710-715, 2018.

[11] H. Jain, B. Palmintier, I. Krad and D. Krishnamurthy, "Studying the Impact of Distributed Solar PV on Power Systems using Integrated Transmission and Distribution Models," 2018 IEEE/PES Transmission and Distribution Conference and Exposition (T\&D), Denver, CO, pp. 1-5, 2018.

[12] S. S. Refaat, H. Abu-Rub, A. P. Sanfilippo and A. Mohamed, "Impact of Grid-Tied Large-Scale Photovoltaic System on Dynamic Voltage Stability of Electric Power Grids," IET Renewable Power Generation, vol. 12, no. 2 , pp. 157-164, 2018.

[13] W. Yi-Bo, W. Chun-Sheng, L. Hua and X. Hong-Hua, "Steady-State Model and Power Flow Analysis of Grid Connected Photovoltaic Power System," 2008 IEEE International Conference on Industrial Technology, Chengdu, pp. 1-6, 2008. 
[14] M. Mouheb, A. Hamidat and L. Loukarfi, "Impact of PV compensation in improving the voltage drop in electrical networks LV," Energy Procedia, vol. 18, pp. 751 - 761, 2012.

[15] A. K. Sinha, V. Shukla and M. Chankaya, "Performance Analysis of Grid connected Solar Farm by Power Factor Control," International Science Press, vol. 9, no. 41, pp. 207-217, 2016.

[16] M. A. Ahmed, S. Kamaruzzaman, C. H. Lim, F. Ahmad, "Performance Evaluation Of Standalone Double Axis Solar Tracking System With Maximum Light Detection MLD For Telecommunication Towers In Malaysia," International Journal of Power Electronics and Drive Systems (IJPEDS), vol 10, no 1, pp. 444-453, 2019

[17] M. Al-Addous, Z. Dalala, C. B. Class, F. Alawneh and H. Al-Taani, "Performance Analysis of Off-Grid PV Systems in the Jordan Valley," Renewable Energy, vol. 113, pp. 930-941, 2017.

[18] IEC, "IEC-61724 Photovoltaic System Performance Monitoring Guidelines for Measurement, Data Exchange and Analysis," Geneva, Switzerland, 1998.

[19] N. National Renewable Energy Lab, "TP-550-38603 Procedure for Measuring and Reporting the Performance of Photovoltaic Systems in Buildings," United States: US Department of Energy, 2005.

[20] N. National Renewable Energy Lab, "CP-520-37358 Performance Parameters for Grid-Connected PV Systems," United States: US Department of Energy, 2005.

[21] IEA, "T2-01, Report IEA-PVPS, TASK 2, Analysis of Photovoltaic Systems," IEA, 2000.

[22] IEA, "T2-05, Report IEA-PVPS, TASK 2, Activity 2.6, Country Reports on PV System Performance," IEA, 2004.

[23] Simon P. Neill, M. Reza Hashemi, "Fundamentals of Ocean Renewable Energy - Generating Electricity from the Sea," Academic Press, 2018

[24] A. Woyte., M. Richter., D. Moser., S. Mau. and N. Reich., in Proceedings of the 28th European Solar PV Conference and Exhibition, Paris, France, 2013.

[25] IEA, "Report IEA-PVPS TASK 13-05, Analysis of Long-Term Performance of PV Systems," IEA, 2014.

\section{BIOGRAPHIES OF AUTHORS}

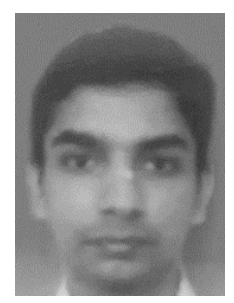

M. Nirrmahl Raj, currently pursuing Masters of Electrical Engineering at Universiti Tenaga Nasional (UNITEN), Malaysia. His main research interests include power system analysis and renewable energy.

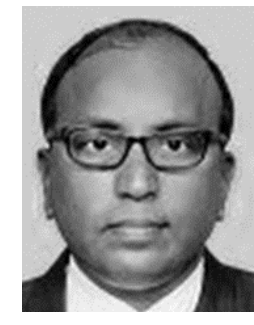

Dr. Jagadeesh Pasupuleti is the Head of Hybrid Renewable Energy Systems, Institute of Sustainable Energy, Universiti Tenaga Nasional, Malaysia. He is a Senior Member of IEEE (USA), Member of IET (UK), Chartered Engineer (UK), Professional Review Interviewer for CEng (UK), Member of EI (UK), Member of BEM (Malaysia) and Member of ISTE (India). He has 32 years of teaching, research and administrative experience. He has supervised 30 postgraduate students, published 100 papers and involved in 40 research and consultancy projects funded around $\$ 2$ million in renewable energy. His research interests include power system, hybrid renewable energy systems, smart grid, energy efficiency, electricity markets and demand side response. 